\title{
LA CULTURA JURÍDICA Y LOS SISTEMAS DE SIGNIFICA- CIÓN JURÍDICA (NORMA, CIENCIA Y FILOSOFÍA)
}

LEgAL CULTURE AND LEGAL SIGNIFICATION SYSTEMS (NORM, SCIENCE AND PHILOSOPHY)

FRANCISCO RUBÉN QUIÑóNEZ HUÍZAR ${ }^{1}$

Resumen: Este artículo tiene como principal finalidad estudiar el concepto de cultura jurídica como parte de los tres significados de lo jurídico, es decir, la norma jurídica, la ciencia jurídica y la filosofía jurídica. No obstante, también se presenta un enfoque hacia la evolución del concepto "cultura"; se analizan los términos "cultura" y "civilización", a fin de clarificar las semejanzas y diferencias. Asimismo, se estudia el concepto de sistema y de sistema jurídico. Dentro del sistema jurídico se hace la distinción con el orden jurídico, así como el origen y cambio de un sistema normativo por otro. De igual forma, se analiza la relación entre sistema jurídico y dogmática jurídica, para concluir con la definición de cultura jurídica como visión integral del sistema normativo, científico y filosófico.

Palabras clave: Cultura, civilización, cultura jurídica, sistema jurídico, orden jurídico, norma jurídica, ciencia jurídica, filosofía jurídica.

Abstract: The main purpose of this article is to study the concept of legal culture as part of the three meanings of the legal, namely the legal norm, legal science and legal philosophy. However, there is also a focus on the evolution of the "culture" concept; the terms "culture" and "civilization" are analyzed to clarify the similarities and differences. The concept of a system and a legal system is also

${ }^{1}$ Doctor en Derecho con mención honorífica por la UNAM. Investigador en temas de Cultura Jurídica y Sistema Jurídico. Catedrático de la División de Estudios de Posgrado de la Facultad de Derecho de la UNAM, del Posgrado del Instituto Nacional de Ciencias Penales y del Instituto de la Judicatura Federal. Catedrático de maestría y doctorado en el Instituto de Estudios Superiores en Derecho Penal, en el Centro de Estudios de Posgrado y en el Instituto Nacional de Desarrollo Jurídico. Miembro del Instituto Mexicano de Historia del Derecho. <fquinonezh@comunidad.unam.mx>. ORCID: <https://orcid.org/0000-00032476-6433>.

Fecha de recepción: 30 de octubre de 2019; Fecha de aprobación: 13 de diciembre de 2019 . 
studied. Within the legal system, the distinction is made with the legal order, as well as the origin and change of one normative system by another. Similarly, the relationship between legal and dogmatic legal system is analyzed, to conclude with the definition of legal culture as a comprehensive vision of the normative, scientific and philosophical system.

Keywords: Culture, civilization, legal culture, legal system, legal order, legal rule, legal science, legal philosophy.

Sumario: I. Introducción; II. Definición de cultura; III. Evolución del concepto "cultura"; IV. Cultura y civilización; V. Significado de "cultura"; VI. ¿Qué se entiende por sistema?; VII. El sistema jurídico; VIII. La norma y el sistema jurídico (validez y eficacia); IX. Diferencia entre "sistema jurídico" y "orden jurídico"; X. Origen y cambio de un sistema jurídico; XI. Sistema jurídico y dogmática jurídica; XII. La cultura jurídica; XIII. Conclusiones; XIV. Fuentes consultadas.

\section{INTRODUCCIÓN}

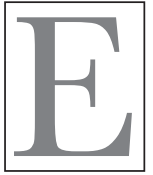

n la actualidad no existe uniformidad de criterios para la definición del concepto o el significado de cultura jurídica. En México, los profesionales del derecho tienen claros los significados del estudio dogmático del derecho, pero, en cuanto al mundo de la cultura jurídica, dicha cuestión no es univoca, ya que su significado oscila entre los estudios del derecho y las ideologías de los juristas, pasando por las actuaciones de los operadores del sistema normativo o, en el peor de los casos, en mi opinión, reduciendo la cultura jurídica a la enseñanza del derecho.

En ese contexto, existe una literatura muy extensa que ha desarrollado de manera directa el tema de la cultura jurídica; asimismo, se encuentran trabajos que de forma indirecta han abordado diversas cuestiones relacionadas con ella. Así, tenemos los estudios de los historiadores, de los historiadores del derecho, los ensayos de carácter antropológico, los estudios de política, y de derecho comparado, sin embargo, nosotros realizaremos un estudio analítico so- 
bre el concepto de cultura y sus diversos significados, después nos adentraremos al estudio del concepto de sistema, para, finalmente, vincular lo cultural con lo jurídico y dar forma al concepto de cultura jurídica.

\section{il. Definición de cultura}

De acuerdo con el Diccionario de la Lengua Española, el término cultura proviene del latín cultura, que significa cultivo. Las distintas acepciones que proporciona son: "Resultado o efecto de cultivar los conocimientos humanos y de afinarse por medio del ejercicio las facultades intelectuales del hombre; conjunto de modos de vida y costumbres, conocimientos y grado de desarrollo artístico, científico, industrial, en una época o grupo social; conjunto de manifestaciones en que se expresa la vida tradicional de un pueblo." 2

Asimismo, el vocablo cultura es un sufijo que significa cultivo. También es el conjunto conocimientos no especializados, adquiridos por una persona mediante el estudio, las lecturas, los viajes, etc.; conjunto de los conocimientos, grado de desarrollo científico e industrial, estado social, ideas, arte, etc., de un país o una época: la cultura clásica, la cultura moderna. ${ }^{3}$

De igual forma, se dice que "la cultura es, el conjunto de los productos, actos y procesos específicamente humanos. En cuanto cultura objetiva, consiste en un especial mundo de objetos, en un complejo de realidades que, producidas por el hombre, componen a su alrededor un medio o ambiente conforme a su índole, tendencias o necesidades". ${ }^{4}$

2 Real Academia Española, Diccionario de la lengua española, España, 2012, pp. 440 y 441 .

${ }^{3}$ Moliner, María, Diccionario del uso del español, Editorial Gredos, Vol. A-G, España, 2013, p. 841.

${ }^{4}$ Larroyo, Francisco, "En memoria de Francisco Romero", Dianoia. Anuario de 
La cultura se puede definir como un conjunto trabado de maneras de pensar, de sentir y de obrar más o menos formalizadas, que, aprendidas y compartidas, por una pluralidad de personas, sirve de un modo objetivo y simbólico a la vez, para constituir a esas personas en una colectividad particular y distinta. ${ }^{5}$

Rocher habla de cultura como un sistema, ya que existe una relación entre los elementos que componen la cultura, no encontrándose solamente yuxtapuestos unos a otros, pues están unidos por unas relaciones de coherencia que los aglutinan. ${ }^{6}$ Esta visión es muy interesante, ya que señala que cuando en la cultura se producen cambios substanciales, los mismos repercuten en otros sectores de la sociedad.

Asimismo, García Rivas señala que las culturas de las sociedades no constituyen un conjunto disperso o incoherente de rasgos yuxtapuestos, sino que sus diversos elementos son interdependientes y se articulan formando una estructura. Es decir, una cultura es un sistema en el cual los elementos están ligados entre sí por determinadas relaciones, de las que unas están en función de otras. Esto implica además, una cierta jerarquización en cuanto a la importancia relativa de los elementos que la integran. ${ }^{7}$

De lo anterior, podemos decir que la cultura es entendida como el resultado o efecto de cultivar los conocimientos humanos y de afinar o desarrollar por medio de ejercicio las facultades intelectuales del hombre. Tal es el sentido ordinario de la cultura; no obstante, en la sociología, antropología y etnología, el vocablo cultura

Filosofía, UNAM-FGE, Año IX, Num. 9, México, 1993, p. 197.

${ }^{5}$ Rocher, Guy, Introducción a la sociología general, $11^{\mathrm{va}}$ edición, Editorial Herder, Barcelona España, 1990, pp. 111 y 112.

6 Ídem. p. 116.

${ }^{7}$ García Rivas, Heriberto, Historia de la Cultura en México, Textos Universitarios México, 1990, p. 18. 
adquiere un significado más amplio, y distinto al común, pues se refiere siempre a una colectividad.

Por tanto, la cultura es un sistema de pensamientos, sentimientos, actitudes y acciones, que posee o lleva a cabo una sociedad, que la hace poseer características peculiares y distintas, que la convierten en única.

\section{Evolución del concepto "cultura"}

El vocablo "cultura", de uso tan generalizado en la actualidad ha sufrido cambios en su significado según la época y el país. Por ejemplo, en Italia, en el siglo XV la palabra cultura se emplea como parte de cultivo, para indicar que [el campo o la tierra] haya sido mudado en hermosa cultura y utilidad pública; en Francia, en la edad media, el término culture significaba el culto religioso. Se empleaba couture o coture para designar un campo labrado y sembrado. El verbo culturer, y cuouturer también indicaba la acción de cultivar la tierra. ${ }^{8}$ Hasta el siglo XVII, el término francés culture indicaba el trabajo de la tierra.

El concepto francés culture pasó al alemán primero como Cultur y después se transformó en Kultur. Comienza a ser utilizado en Alemania a fines del siglo XVIII en estudios de "historia universal". Dichos estudios se proponían reconstituir una historia general de la humanidad y de las sociedades desde sus orígenes, sin embargo, a estos historiadores les impulsaba una notable curiosidad sobre las diversas sociedades y civilizaciones, llegando a convencerse de que la historia humana es también la historia del progreso de la humanidad y que el estudio comparado de las sociedades y de las civilizaciones revelaba la evolución seguida por el progreso. ${ }^{9}$ Es así como surge el concepto de cultura como una idea de progreso o evolución de la humanidad.

\footnotetext{
${ }^{8}$ Rocher, Guy. Introducción a la sociología general, Op. Cit., p. 195.

${ }^{9}$ Ibídem, p. 104.
} 
No obstante, fue hasta el siglo XVIII, cuando los escritores franceses comenzaron a utilizar el término para designar la formación del espíritu ${ }^{10}$. En esta época el término designa el progreso intelectual de una persona, o también el trabajo necesario a ese progreso. Traducido nuevamente al alemán, el término culture cobra un sentido más amplio, designando el progreso intelectual y social del hombre en general, de las colectividades, de la humanidad, recibiendo por vez primera una connotación colectiva, pero con la idea de un mejoramiento.

Pasando al inglés, la noción de cultura sufre otra transformación. A la antropología inglesa se debe esa connotación, con E. B. Tylor, cuya obra Primitive Gulture apareció en 1871. Inspirándose sobre todo en los estudios de Gustav Klemm, quien había publicado en diez volúmenes, una monumental Historia universal de la cultura de la humanidad, seguida de dos volúmenes sobre la Ciencia de la cultura, Tylor extrajo los elementos que necesitaba para componer su noción de cultura, que empleó como sinónimo de civilización; asimismo, proporciona una definición del término: "La cultura es ese conjunto complejo que abarca los conocimientos, las creencias, el arte, el derecho, la moral, las costumbres y los demás hábitos y aptitudes que el hombre adquiere en cuanto miembro de la sociedad". ${ }^{11}$

De acuerdo con Guy Rocher, esta definición ofrece la novedad y la particularidad de no referirse a la cultura como un progreso o un devenir, ya que se presenta como un conjunto de hechos directamente observables en un momento dado del tiempo y comporta la posibilidad de seguir su evolución. ${ }^{12}$ Con ello, la noción antropológica de cultura había nacido.

${ }^{10}$ Fabvre, Lucien, et al, Civilisation: le mot et l'idée, France, Centre Internacional de Synthé, 1930, p 88 y ss, citado por Rocher, Guy. Introducción a la sociología general, Op. Cit., p. 195.

${ }^{11}$ Cfr. Tylor, Edward Burnett, Primitive culture, USA, Vol. I, Dover publications, 2016, pp. 19 a 40.

12 Ídem. 
En Estados Unidos, por su parte, la antropología ha llegado incluso a definirse como la ciencia de la cultura, mientras que en Inglaterra se distingue entre antropología física (estudio del desarrollo y crecimiento del cuerpo humano) y antropología social (estudio de los pensamientos, actitudes y sentimientos); no obstante, los norteamericanos prefieren llamar antropología cultural a la antropología social. ${ }^{13}$

En sociología el término "cultura" fue rápidamente adoptado por los primeros sociólogos norteamericanos, sin embargo, tardó más en abrirse camino que en antropología, debido a que los grandes precursores de la sociología, Comte, Marx, Weber, Durkheim, no lo emplearon. Pero hoy en día forma parte de la terminología tanto de la antropología como de la sociología.

iv. Cultura y Civilización

La evolución del término "cultura" como venía entendiéndose se confronta con la noción de civilización. Ya que el vocablo "cultura" vino a adquirir un sentido muy próximo al que poseía el término "civilización". No obstante que cultura y civilización se suelen emplear indistintamente, para expresar un mismo concepto, podemos decir que el concepto "cultura", es más limitado en el tiempo y en el espacio que el término "civilización".

En sus orígenes la palabra "civilización" no significó lo mismo en distintos países de Occidente. En especial, hay una diferencia entre el uso francés e inglés y el significado alemán. En Francia e Inglaterra, el concepto resumía el orgullo que inspira la importancia que tiene la nación propia en el conjunto de progreso de Occidente y de la humanidad en general. En el ámbito germano-parlante "civilización" significaba algo muy útil pero con un valor de segundo grado, algo que

13 Ídem. 
afecta únicamente a la exterioridad de los seres humanos. La palabra con la que se interpretan a sí mismos los alemanes y que expresa el orgullo por la contribución propia y por la propia esencia es "cultura". ${ }^{14}$

Para Norbert Elías, el concepto de "civilización" se refiere a hechos muy diversos: tanto al grado alcanzado por la técnica como al tipo de modales reinantes, al desarrollo del conocimiento científico, a las ideas religiosas y a las costumbres, y concluye que la generalidad con que se pueden designar las acciones y actitudes humanas es el término "civilización". ${ }^{15}$

Los procesos históricos que han conducido a que, particularmente, Occidente se identifique como "civilizado" se remontan al siglo XVI, y aun a la Edad Media, para poner en evidencia un complejo movimiento de pautas de comportamiento que se extenderá hasta los siglos XVIII y XIX. Este movimiento de restricción y transformación de los comportamientos estimuló el cambio de los grupos aristocráticos caballerescos hacia los de la aristocracia cortesana. Se trató de regulaciones estrictas a la conducta de los caballeros para lograr diferenciarse de los grupos inferiores de la sociedad campesina y responder a nuevas funciones en los cuerpos estatales de las cortes que se unificaban bajo la aparición de estados centralizados. ${ }^{16}$

El proceso de la civilización es una historia de las costumbres que han posibilitado el hecho sociológico de ser "civilizado"; decir que alguien es civilizado no implica un señalamiento de que sea bueno o malo, sino que se está expresando un hecho sociológico. ${ }^{17}$ En el que la persona sigue ciertas reglas sociales dentro de un contexto de urbanidad.

${ }^{14}$ Cfr. Elias, Norbert. El proceso de la civilización. Investigaciones sociogenéticas y psicogenéticas. México, Fondo de Cultura Económica, 2012, p 137.

15 Ibídem, p. 131.

16 Ídem.

17 Ídem. 
Según Braudel, el concepto de civilización, surge a lo largo del siglo XVIII, e inicialmente se identificó con la forma de vida y los conocimientos de las sociedades avanzadas, contraponiéndose al término de barbarie que se atribuía a la forma de vida y los conocimientos de los pueblos colonizados o más atrasados. ${ }^{18}$

Para Huntington una civilización es la entidad cultural más amplia. Aldeas, regiones, grupos étnicos, nacionalidades, grupos religiosos, todos tienen culturas distintas con diferentes grados de heterogeneidad cultural. Así una civilización es el agrupamiento cultural humano más elevado y el grado más amplio de identidad cultural que tienen las personas. Se define por elementos objetivos comunes, tales como la lengua, historia, religión, costumbres, instituciones y por la autoidentificación subjetiva de la gente. ${ }^{19}$

Duverger sustenta la tesis de que los conjuntos culturales se van articulando históricamente de forma diferenciada, aunque siguiendo patrones o pasando por estadios análogos, que permiten contemplarlos como partes de agrupaciones más amplias a las que denomina "civilizaciones". Para este autor, las civilizaciones son realidades sociales surgidas históricamente como consecuencia de la aglutinación de los conjuntos culturales, o por evolución de alguno de ellos, precisamente, a partir de los elementos comunes que existen en sus creencias, instituciones, técnicas, condiciones geográficas y demográficas. ${ }^{20}$

"La civilización es cultura, pero no toda cultura es civilización"21 La civilización es así un momento o un corte de las relaciones so-

18 Braudel, Fernand, Las civilizaciones actuales. Estudio de la historia económica y social, España, Tecnos, 1999, pp. 12-14.

${ }^{19}$ Huntington; Samuel, El Choque de Civilizaciones y la Reconfiguración del Orden Mundial, España, Paidós, 1 ${ }^{\text {ra }}$. Edición, 1997, p. 48.

20 Duverger, Maurice, Sociología política, España, Editorial Ariel. $3^{\text {ra }}$ edición, 1980, pp. 127-128.

21 Odum, Howard W., Understanding society; the principles of dynamic sociology. England, Macmillan, 1947, p. 288. 
ciales o un producto histórico de algunas culturas, de aquellas que precisamente optaron por lo urbano y sus concomitancias o fueron forzadas a ello (recuérdese que la conquista de América fue urbana, se realizó a partir de la fundación intencional de ciudades entre culturas preexistentes, muchas de las cuales tenían ciudades y habían tenido o estaban en pleno desarrollo civilizatorio.

Por tanto, la noción de cultura se refiere a una sociedad dada e identificable que aglutina las creencias, instituciones, técnicas, ciencia, derecho, economía, política, etcétera; mientras que el término civilización sirve para designar un conjunto de sociedades o culturas; o bien, un tipo de sociedad cuya característica principal es su complejidad social manifestada en lo urbano; o también, en una época histórica, civilización se asoció al significado de Occidente. ${ }^{22}$

En el siguiente cuadro se clarifican los significados en que cultura y civilización son iguales y aquellos en los que difieren.

\begin{tabular}{|l|}
\hline \multicolumn{1}{|c|}{ CULTURA Y CIVILIZACIÓN } \\
\hline SEMEJANZAS \\
\hline $\begin{array}{l}\text { Conjunto de maneras de pensar, sentir y actuar de una sociedad de- } \\
\text { terminada (lengua, historia, religión, costumbres, derecho, institucio- } \\
\text { nes, etcétera). }\end{array}$ \\
\hline
\end{tabular}

22 La cultura o civilización occidental tiene cuatro ismos que la identifican y la diferencian del resto del mundo: judeo-cristinanismo, racionalismo, capitalismo y constitucionalismo. El judeo-cristianismo, es la base del comportamiento y de las categorías del bien y del mal en Occidente, difundido en el mundo por la conversión del imperio romano. El racionalismo, constituye la interpretación de la realidad con objetividad, que hunde sus raíces en la sociedad griega con la ciencia y la filosofía. El capitalismo, es el modo de producción que establece las reglas del mercado, adoptado por el Occidente durante la Edad Media, que ha ido evolucionando y que sigue vigente. El constitucionalismo, que se adoptó a partir de los postulados de la Independencia de los Estados Unidos de América y de la Revolución Francesa que generó el Estado Moderno y el Estado de Derecho. 


\begin{tabular}{|l|l|}
\hline \multicolumn{2}{|c|}{ DIFERENGIAS } \\
\hline \multicolumn{1}{|c|}{ CULTURA } & \multicolumn{1}{|c|}{ CIVILIZACIÓN } \\
\hline $\begin{array}{l}\text { Diversas culturas pueden integrar } \\
\text { una civilización. }\end{array}$ & $\begin{array}{l}\text { La civilización está integrada por } \\
\text { varias culturas. }\end{array}$ \\
\hline $\begin{array}{l}\text { La cultura es característica de cual- } \\
\text { quier sociedad, por pequeña que } \\
\text { sea. }\end{array}$ & $\begin{array}{l}\text { Civilización es una sociedad con } \\
\text { un grado de avance significativo, } \\
\text { basado en lo urbano. }\end{array}$ \\
\hline $\begin{array}{l}\text { El concepto cultura se utiliza tan- } \\
\text { to para sociedades desarrolladas } \\
\text { como no desarrolladas. }\end{array}$ & $\begin{array}{l}\text { El término civilización se ha iden- } \\
\text { tificado como sinónimo de pro- } \\
\text { greso y desarrollo. }\end{array}$ \\
\hline $\begin{array}{l}\text { El concepto cultura se ha usado } \\
\text { para identificar tanto grupos occi- } \\
\text { dentales como no occidentales. }\end{array}$ & $\begin{array}{l}\text { El concepto civilización ha sido } \\
\text { utilizado para identificar a las so- } \\
\text { ciedades occidentales. }\end{array}$ \\
\hline
\end{tabular}

\section{v. Significado de "Cultura"}

Cultura es el nombre común para designar todos los tipos de conducta socialmente adquiridos y que se transmiten con igual carácter por medio de símbolos; por ello, es un nombre adecuado para todas las realizaciones características de los grupos humanos; en él se comprenden, no sólo particulares tales como el lenguaje, la construcción de instrumentos y la religión, sino también los instrumentos materiales o artefactos en los que se materializan las realizaciones culturales y mediante los cuales surten efecto práctico los aspectos intelectuales de la cultura, como los edificios, instrumentos, máquinas, artificios para la comunicación, objetos de arte, etc. ${ }^{23}$ De ahí que, la cultura se integre tanto por elementos subjetivos como por elementos objetivos.

${ }^{23}$ Diccionario de Sociología, primera edición, cuarta reimpresión, T. II, trad. T. Muñoz et al, FGE, México, 1971, p. 75. 
La significación científica del término es, por consiguiente, completamente diferente de su acepción popular. Comprende todo lo que es aprendido mediante comunicación entre hombres. Abarca toda clase de lenguaje, tradiciones, usos, costumbres e instituciones. Como jamás se ha tenido noticia de un grupo humano que no tuviera lenguaje articulado, éste se convierte en la característica distintiva y universal de las sociedades humanas. ${ }^{24}$

Asimismo, como ningún grupo animal posee lenguaje verbal -el principal vehículo para la difusión de la cultura- el origen de la cultura como rasgo humano puede encontrarse en la superior capacidad del hombre para adquirir conocimientos mediante la experiencia y para comunicar lo aprendido por medio de símbolos, el principal de los cuales es el lenguaje. Por ello, el lenguaje de un pueblo o de una nación no se limita a exteriorizar el pensamiento de sus miembros: ambos se desenvuelven a la par. En ese sentido, ciertamente, el lenguaje es la manifestación del espíritu de un pueblo. ${ }^{25}$

El descubrimiento y la invención forman el contenido del aprendizaje del hombre y la acumulación y transmisión de ellos mediante procesos de enseñanza y aprendizaje da como resultado el desarrollo de la cultura característica de cada grupo humano.

Como la cultura se transmite mediante procesos de enseñanza y aprendizaje, tanto formales como informales, la parte esencial de la cultura se encuentra en las pautas incorporadas a las costumbres

${ }^{24}$ La principal característica del lenguaje humano estriba en la simbología y los significados de la realidad que ella participa; en el significado de los símbolos tiene mucho que ver la ideología. Para Norbert Elías el concepto de "figuración" sirve para proveerse de un sencillo instrumento conceptual con ayuda del cual se puede flexibilizar la presión social que induce a hablar y pensar como si "individuo" y "sociedad" fuesen dos figuras no sólo distintas sino, además, antagónicas. Cfr. Elías, Norbert. Sociología fundamental, Gedisa Editorial, México, 2011, p. 154 y ss.

${ }^{25}$ Acero, Juan José, "Introducción: concepciones del lenguaje", Filosofía del lenguaje I. Semántica, Editorial Trota, España, 1998, p. 15. 
sociales del grupo; es decir, en los conocimientos, ideas, creencias, valores, normas y sentimientos que prevalecen en el mismo. La parte ostensible de la cultura se encuentra en la conducta efectiva del grupo, esto es, en los usos, costumbres e instituciones. Pero las costumbres y las instituciones son casi siempre expresiones de las ideas, creencias, valores y sentimientos del grupo.

Ahora bien, sociedad y cultura son términos relacionados, no pudiendo existir sociedad sin cultura, ya que la sociedad a través de sus modos de pensar de sentir y de obrar, determinará el tipo de cultura.

Antes de finalizar este punto, debemos distinguir el significado del término cultura tanto en el lenguaje científico como en el ordinario. Cuando se hace alusión a la cultura de un individuo, en el lenguaje de la ciencia, se vincula en forma inmediata con la sociedad a la cual pertenece. Si por el contrario, se habla de que una persona es culta, esta expresión se sitúa en el lenguaje ordinario y significa que su acervo de conocimientos es amplio. Por ello, la expresión de que un sujeto es inculto no significa que no tenga cultura, ya que todo individuo que pertenezca a una sociedad la posee, sino que no se ha puesto el cuidado necesario para su desarrollo espiritual o académico.

Por tanto, la cultura en el lenguaje científico, aun cuando aluda al individuo en particular, no es por naturaleza singular, sino que siempre se referirá a una colectividad de personas. Es decir, la cultura es un término que en la ciencia hace alusión a los grupos sociales no a la persona. De ahí que se considere un sistema social.

VI. ¿QUÉ SE ENTIENDE POR SISTEMA?

Antes que todo, debemos aclarar a qué nos referimos cuando hablamos del concepto sistema, ya que dicho término no es unívoco. 
De acuerdo con el Diccionario de la Real Academia Española, la palabra "sistema" significa por un lado, un conjunto de reglas o principios sobre una materia racionalmente enlazados entre sí; asimismo, es entendida como un conjunto de cosas que ordenadamente relacionadas contribuyen a determinado objeto. ${ }^{26}$ Como se puede apreciar la principal característica en la anterior definición es la relación de principios, reglas o cosas, así como el orden entre ellos.

Para Ferrater Mora un sistema es un conjunto de elementos relacionados entre sí funcionalmente, de modo que cada elemento es función de algún otro, no habiendo ningún elemento aislado. El término "elemento" es neutral y puede entenderse por él una entidad, una cosa, un proceso, [una norma], etc. ${ }^{27}$

Por su parte, el diccionario de María Moliner señala que un sistema es un conjunto ordenado de normas y procedimientos con que funciona o se hace funcionar una cosa: Sistema político o sistema educativo; asimismo, es un conjunto de cosas que se mueven, actúan u obran coordinadamente: el sistema solar, por ejemplo. $\mathrm{O}$ bien, un conjunto orgánico de principios e ideas sobre una materia determinada: sistema filosófico. ${ }^{28}$

Jean Lugan señala que un sistema es una unidad global organizada de interrelaciones entre elementos, acciones o individuos. ${ }^{29}$ En esta definición se representa el pensamiento de autores que consideran a la unidad como la característica esencial del sistema, en donde las interrelaciones que mantienen los elementos, las acciones o los individuos no se encuentran simplemente yuxtapuestos.

Por otro lado, hablando de sistema, no podíamos dejar de lado

${ }^{26}$ Real Academia Española, Diccionario de la Lengua Española, op. cit., p. 1888.

${ }^{27}$ Ferrater Mora, José, Diccionario de Filosofia, Tomo IV, (Q-Z), España, Editorial Ariel, 2004, p. 3305.

${ }^{28}$ Moliner, María, Diccionario del uso del español, Tomo II, (J-Z), España, Editorial Gredos, 2007, p. 2734.

${ }^{29}$ Lugan, Jean Claude, La systémique sociale, France, Presses Universitaries de 
la concepción de Luhmann, quien dentro de la teoría de sistemas sociales establece un nuevo paradigma. ${ }^{30}$ Para este autor, lo que caracteriza al sistema, a diferencia de los teóricos anteriores, no es únicamente su unidad, sino la diferencia entre sistema y entorno. Un sistema diferenciado ya no consta propiamente de un determinado número de partes y de relaciones entre dichas partes, sino más bien, de un mayor o menor número de diferencias operativamente utilizables entre el sistema y su entorno. ${ }^{31}$

La determinación de los elementos de un sistema plantea el problema de sus fronteras; es decir, saber establecer hasta dónde llega el sistema y donde comienza el entorno. Este último, es entendido como el conjunto de elementos que no pertenecen al sistema y cuyo estado es susceptible de afectar o de ser afectado por el sistema. ${ }^{32}$

Luhmann define al sistema como la diferencia entre sistema y entorno. El mismo autor señala que el concepto de sistema aparece en la definición duplicado en el concepto de diferencia. Por tanto toda su teoría está sustentada en una disposición sobre la diferencia entre sistema y entorno. ${ }^{33}$

La concepción de Luhmann es sumamente importante, pues desde su definición de sistema se pueden englobar, no solamente los que conciernen a la ciencia, sino cualquier tipo de sistema cuya unidad de sus elementos permite diferenciarlo del entorno.

France, 2009, pp. 32-50.

${ }^{30}$ La característica de la teoría de sistemas de Luhmann, en el marco de la sociología moderna, estriba en la pretensión de que la disciplina social se convierta en una reflexión sistemática.

${ }^{31}$ Cfr. Luhmann, Niklas, Sistemas Sociales. Lineamientos para una teoría general, México, Universidad Iberoamericana-Alianza Editorial, 1991, p. 30.

32 Ídem.

${ }^{33}$ Luhmann, Niklas, Introducción a la teoría de sistemas, Universidad Iberoamericana, México, 2009, p. 78. 
Desde luego que la teoría de Luhmann no puede ser resumida en unos cuantos párrafos, además de que la intención de nuestro trabajo no es analizar la teoría de sistemas sino vincular el concepto de sistema con el derecho.

Todos los sistemas tienen en común el hecho de que sus elementos constituyentes son compatibles y de que todos los elementos están determinados entre sí. ${ }^{34}$ Lo anterior significa que, cuando varios elementos tienen un origen común, así como una conexión entre sí se puede para determinar un sistema.

Es difícil alcanzar una definición de sistema que satisfaga los numerosos empleos del concepto en un solo apartado; sin embargo, para los fines de este trabajo, diremos que un sistema es un conjunto de elementos que tienen un origen común, los cuales se encuentran relacionados y forman parte de un todo.

\section{EL SISTEMA JURÍdICO}

Hablar de sistema jurídico significa que el derecho puede constituir un sistema. ${ }^{35}$ Un sistema como ya lo señalamos está conformado por un conjunto de elementos que no se encuentran simplemente yuxtapuestos, sino que forman una unidad como consecuencia de sus relaciones.

En el caso específico del derecho, su estudio como sistema comienza a ser difundido por Kelsen, para quien "El derecho es un orden de la conducta humana. Un 'orden' es un conjunto de normas. El derecho no es, como a veces se dice, una norma. Es un con-

${ }^{34}$ Stebbing, Susan, Introducción moderna a la lógica, Centro de Estudios Filosóficos-UNAM, México, 1985, p. 231.

${ }^{35} \mathrm{El}$ derecho, desde un punto de vista sistémico, se visualiza como un conjunto ordenado de normas jurídicas, de tal manera que se constituyen en los elementos del sistema; las cuales se encuentran vinculadas entre sí, generalmente por una constitución. Cfr. Huerta, Carla, Constitución, transición y ruptura, Op. Cit., p. 69. 
junto de normas que tienen el tipo de unidad a que nos referimos cuando hablamos de un sistema". ${ }^{36}$

Sin embargo, de la interpretación de teorías anteriores a la de Kelsen, tal es el caso de la de John Austin, también se puede desprender una concepción sistémica del derecho. "Consideradas como una totalidad y como relacionadas y conexas las unas con las otras, las leyes y normas positivas de una comunidad particular o específica constituyen un sistema o cuerpo de Derecho. Y en tanto que limitada a uno o cualquiera de tales sistemas o a alguna de sus partes, la Jurisprudencia es particular o nacional". ${ }^{37}$

No obstante, es a partir de Kelsen, que los juristas y filósofos del Derecho han intentado construir una teoría del sistema jurídico, ${ }^{38}$ la cual, desde luego, no ha sido uniforme, pues la concepción del sistema depende de la postura metodológica desde la cual se analiza la normatividad.

${ }^{36}$ Kelsen, Hans, Teoría General del Derecho y del Estado, Trad. de Eduardo García Máynez, UNAM, México, 1998, p. 3.

37 Austin, John, Sobre la utilidad del estudio de la jurisprudencia, México, Supremo Tribunal de Justicia del Estado de Sinaloa, 1998, p. 1.

${ }^{38}$ Además de Kelsen, existen otros autores que tratan de explicar el derecho como sistema, entre los cuales se encuentran: Hart, H. L. A. El Concepto del Derecho, trad. de Genaro Carrio, segunda edición, México, Editora Nacional, 1980; Raz, Joseph, El concepto de sistema jurídico, Op. Cit.; Kerchove, Michel van der y Ost François, El sistema jurídico entre orden y desorden, trad. Isabel Hoyo Sierra, España, Servicios de publicaciones de la Facultad de Derecho, Universidad Complutense de Madrid, 1997; Friedman, Lawrence, The Legal System, A Social Science Perspective, Rusell Sage Foundation, U.S.A., 1975; Luhmann, Niklas, Sistemas Sociales, lineamientos para una teoría general, Op. Cit.; Tamayo y Salmorán, Rolando, Sobre el sistema jurídico y su creación, UNAM-IIJ, México, 1976; Alchourrón, Carlos y Bulygin, Eugenio, Análisis Lógico y Derecho, España, Centro de Estudios Constitucionales, 1991; Tarello Giovanni, Cultura jurídica y política del derecho, trad. de Isidro Rosas Alvarado, México, Fondo de Cultura Económica, 1995; Adomeit, Klaus, Introducción a la teoría del derecho, lógica normativa, teoría del método, politología jurídica, España, Editorial Civitas, 1984. 
Como señala Raz, el término "sistema jurídico" no es un término técnico. Ciertamente, en ocasiones puede figurar en resoluciones de los tribunales, pero, en realidad, cualquier término puede aparecer en ellas; y, aunque ocasionalmente es usado en la argumentación jurídica de los operadores derecho, éste no tiene el carácter de término jurídico. Tampoco es un concepto importante en la diaria administración del derecho como lo son los conceptos de contrato, propiedad, derecho subjetivo, deber y otros semejantes. El término es utilizado cuando se piensa sobre el derecho y no cuando se usa o se aplica el derecho. ${ }^{39}$

Para la focalización de los fenómenos jurídicos, una de las primeras cosas que hay que comprender es que el material normativo no se produce de manera aislada: el derecho se manifiesta a través de un sistema y las normas sólo adquieren su significado real cuando se las ubica en la perspectiva de un determinado orden jurídico. ${ }^{40}$

Así las cosas, el derecho como sistema tiene como elemento fundamental a la norma jurídica. Necesariamente al hablar de sistema jurídico tenemos que hacer alusión a las normas jurídicas; ${ }^{41}$ donde esas normas se encuentran relacionadas por una fuente común, constituida por una norma que da fundamento al sistema. ${ }^{42}$

${ }^{39}$ Cfr. Raz, Joseph, La autoridad del derecho. Ensayos sobre derecho y moral, México, UNAM-IIJ, 1982, p. 106.

${ }^{40}$ Cfr. Raz, Joseph, El concepto de sistema jurídico, Op. Cit., p. 17 y ss.

41 El término norma proviene del latín norma el cual designa un mandamiento, un reglamento, o una orden; sin embargo, la norma también puede decretar, permitir, autorizar y derogar. Vid. Kelsen, Hans, Teoría General de las Normas, México, México, Trillas, 1994, p. 19.

42 Llámese Soberano (Austín); Constitución o Norma Fundamental (Kelsen); Regla de Reconocimiento (Hart); Órganos Primarios (Raz); Acto-Condición (Ta- 
VIII. LA NORMA Y EL SISTEMA JURÍdico (VALIDEZ Y EFICACIA)

La validez y la eficacia son los conceptos que vinculan las normas jurídicas y el sistema jurídico.

Parafraseando a Liborio Hierro "no hay estudio sobre la validez donde no aparezca de una u otra forma, alguna referencia a la eficacia" y "por cada frase escrita sobre la eficacia de las normas jurídicas hay al menos un centenar dedicado a la validez." 43

Según Kelsen, por validez se entiende la existencia específica de las normas. Decir que una norma es válida equivale a declarar su existencia o lo que es lo mismo, a reconocer que tiene fuerza obligatoria frente a las personas cuya conducta regula. ${ }^{44}$

Alf Ross señala también que el concepto de validez se ha usado para indicar la existencia de una norma o de un sistema de normas. La validez de una norma, en este sentido, significa su existencia efectiva o real, por oposición a una regla meramente imaginada o a un mero proyecto. ${ }^{45}$

Por su parte, una norma es eficaz cuando se produce una correspondencia entre la conducta real de ciertos sujetos y la conducta que una norma establece; esto es, si la acción que la norma prescribe es, en la realidad, la acción que realizan los destinatarios de la norma. ${ }^{46}$

"Las definiciones del concepto del derecho orientadas a la eficacia se encuentran, sobre todo, en la vecindad de las teorías sociológicas y realistas de derecho. Se diferencian según que apunten al

mayo).

${ }^{43}$ Hierro, Liborio, La eficacia de las normas jurídicas, México, Distribuciones Fontamara, 2010, p. 193.

${ }^{44}$ Kelsen Hans, Teoría General del Derecho y del Estado, Op. Cit., p. 35.

45 Ross, Alf, El concepto de validez y otros ensayos, México, Distribuciones Fontamara, 1991. p.26.

${ }^{46}$ Hierro, Liborio, La eficacia de las normas jurídicas, Op. Cit., p. 78. 
aspecto externo o formal o al aspecto interno (motivación) de una norma o de un sistema normativo." 47

Según Alexy, el aspecto externo de una norma consiste en la regularidad de su cumplimiento y/o de la sanción de su incumplimiento. Lo decisivo es el comportamiento. Por su parte, el aspecto interno de una norma consiste en la motivación de su cumplimiento y/o aplicación. ${ }^{48}$

Siguiendo las ideas de Kelsen, la validez y la eficacia son conceptos enteramente distintos, sin embargo, existe entre ellos una relación muy importante. Una norma es considerada como válida sólo bajo la condición de que pertenezca a un sistema normativo, a un orden que, considerado en su totalidad, es eficaz. Así pues, la eficacia es condición de validez, pero no la razón de la misma. ${ }^{49}$

En ese sentido, una norma no es válida porque es eficaz; es válida si el orden al cual pertenece tiene, en general, eficacia. Esta relación entre validez y eficacia sólo es entendible desde una postura que se ocupe del estudio de las normas como parte de un orden jurídico. ${ }^{50}$

Ahora bien, siguiendo a Carla Huerta, "una cuestión distinta es la existencia del sistema, que depende principalmente de su eficacia, es decir, de que sus normas sean generalmente observadas y aceptadas por los órganos aplicadores, por los sujetos a quienes se aplican, y por la posibilidad de accionar el monopolio de la fuerza estatal". 51

${ }^{47}$ Alexi, Robert, El concepto y la validez del derecho, España, Editorial Gedisa, 1997 , p. 22.

${ }^{48}$ Ibídem, p. 23.

${ }^{49}$ Kelsen, Hans, Teoría General del Derecho y del Estado, Op. Cit., p. 48.

50 Ídem.

${ }^{51}$ Huerta, Carla, "Constitución, transición y ruptura”, Transiciones y diseños institucionales, María del Refugio González y Sergio López Ayllón compiladores, UNAM-IIJ, México, 1999, p. 65. 
El sistema jurídico es calificado como válido en virtud de su eficacia y legitimidad. Hay ciertas condiciones necesarias para la existencia de un sistema jurídico: que la validez de sus normas pueda ser comprobada conforme a un cierto criterio del sistema, que sean generalmente obedecidas, así como que las reglas secundarias sean efectivamente aceptadas por los funcionarios. ${ }^{52}$

Las siguientes son algunas posiciones teóricas que indican la relación entre validez y eficacia de las normas jurídicas:

1. La validez es la forma de existir las normas jurídicas y la eficacia como cumplimiento y aplicación es condición necesaria de la validez (Hans Kelsen).

2. La eficacia como aplicación es la forma de existir las normas jurídicas y la validez es condición necesaria de la eficacia (Alf Ross).

3. La validez y la eficacia son dos dimensiones independientes de las normas jurídicas (Herbert Hart).

En este contexto, según lo afirma Liborio Hierro, la eficacia general del sistema jurídico es, en algún modo, condición de la validez, de la vigencia o de la existencia de las normas jurídicas. ${ }^{53}$

Por lo tanto, una norma eficaz no convierte en eficaz al sistema jurídico; sin embargo, una gran cantidad o la mayoría de normas eficaces, sí lo hace. Por otro lado, una norma aislada puede ser válida aunque no sea eficaz, si ésta fue creada por las reglas del sistema. ${ }^{54}$ Entonces, un sistema jurídico adquiere validez necesariamente a través de la eficacia. La norma jurídica aislada puede ser válida de dos formas: que el sistema formalmente la declare válida o que sea eficaz junto con la mayoría de las normas del sistema; en este caso, el sistema se volverá válido y todas sus normas también.

52 Ídem.

${ }^{53}$ Hierro, Liborio, La eficacia de las normas jurídicas, México, Distribuciones Fontamara, 2010, pp. 193 y 194.

${ }^{54}$ Ibídem, p. 14. 
IX. Diferencia entre "SISTEMA JuRídico" Y "ORDEN JURídico"

Como ya lo señalamos, en apartados anteriores, Kelsen es quien comienza a referirse expresamente al derecho como un sistema, sin embargo, en su teoría, los términos sistema jurídico y orden jurídico son tomados como sinónimos, ya que un orden, señala Kelsen, es un conjunto de normas que tienen el tipo de unidad que corresponde a un sistema..$^{55}$

Por su parte, Joseph Raz habla de sistemas jurídicos y sistemas jurídicos momentáneos, refiriéndose a los primeros como la continuidad de las disposiciones jurídicas del sistema, y a los segundos, como a las disposiciones jurídicas existentes en un momento determinado. ${ }^{56}$

Para Tamayo y Salmorán los conceptos de orden y sistema jurídico son igualmente sinónimos, y no establece ninguna diferenciación entre ellos, al señalar "existe la idea -bastante compartida entre los juristas- de que los comportamientos jurídicos -testamentos, tratados, indultos, embargos, etcétera- forman o constituyen un sistema que es generalmente denominado 'orden jurídico' o bien 'sistema jurídico'. ${ }^{57}$

Por otro lado, Alchourrón y Bulygin señalan que "para evitar la ambigüedad de orden jurídico utilizaremos el término sistema para referirnos a conjuntos de normas y orden en el sentido de secuencia de conjuntos de normas. Un orden jurídico es, de acuerdo a esta convención, una secuencia de sistemas normativos." 58 De tal mane-

${ }^{55}$ Kelsen, Hans, Teoría General del Derecho y del Estado, Op. Cit., p. 3.

${ }^{56} \mathrm{Raz}$, Joseph, El concepto de sistema jurídico, México, UNAM-IIJ, 1986, p. 225 y ss.

${ }^{57}$ Cfr. Tamayo y Salmorán, Rolando, Sobre el sistema jurídico y su creación, UNAMIIJ, México, 1976, p. 93.

58 Alchourron Carlos y Bulygin, Eugenio Análisis lógico y Derecho, España, Centro de Estudios Constitucionales, 1991, p. 397. 
ra que para ellos, el orden es más amplio que el sistema.

Nosotros hemos preferido seguir las ideas de Carla Huerta en cuanto a la distinción entre sistema y orden en el derecho. La diferencia entre sistema jurídico y orden jurídico se explica mediante la diacronía de la vigencia de las normas que integran el primero, es decir las normas pueden ser identificadas no solo por su operatividad en determinado tiempo, sino porque una norma no vigente puede ser aplicada. De tal manera que en el sistema se incluyen no solamente las normas presentes, sino también las del pasado, es decir, validas o no, vigentes o no. ${ }^{59}$

De tal manera que un sistema jurídico está constituido por la totalidad de las normas de un Estado, es decir, un sistema jurídico está conformado por todas las disposiciones jurídicas generadas en un determinado Estado, vigentes y no vigentes.

Por su parte, el orden jurídico permite distinguir los cambios que se producen dentro del sistema. El orden jurídico es sincrónico, ya que se refiere a la aplicación de normas en un momento determinado. ${ }^{60}$

En este orden ideas, el orden jurídico está formado por aquel conjunto de normas vigentes para un momento determinado; es decir, el sistema es el continente de todas las normas que son o han sido vigentes, y los órdenes jurídicos forman el contenido del sistema. No obstante, cada orden jurídico comparte normas con los órdenes anteriores, normas que forman parte del sistema jurídico.

El sistema jurídico es el continente de todas las normas de un país tanto vigentes como no vigentes y el orden jurídico constituye los cortes transversales que generan un nuevo contexto normativo. De tal forma que, un sistema jurídico está conformado por varios órdenes jurídicos; generalmente iniciados a partir de nuevas bases normativas o nuevos documentos constitucionales.

59 Huerta, Carla, "Constitución, Transición y Ruptura”, Transiciones y diseños institucionales, Op. Cit., p. 49 y ss.

${ }^{60}$ Ibídem, p. 67. 
X. Origen y cambio de un sistema jurídico

Para abordar el tema del origen del sistema jurídico, la teoría jurídica hace referencia al concepto de "constitución". La Constitución es la primera norma positiva del sistema, porque establece los procesos y órganos de creación de normas inferiores, así como sus contenidos: obligatorios, prohibidos o permitidos. La Constitución es el parámetro de validez del sistema jurídico. ${ }^{61}$ Además, es la norma de mayor jerarquía.

Según la concepción moderna, la Constitución debe ser considerada como la norma a la que el sistema normativo sujeta la creación de normas, y en función de la unidad del sistema jurídico es considerada no solamente como la norma suprema sino como la base del sistema mismo. ${ }^{62}$

La constitución es, por tanto la norma suprema del ordenamiento de la cual derivan cadenas de validez de producción normativa; constituye el parámetro de validez formal y material del sistema jurídico. Su supremacía radica en el hecho de que es la base sobre la cual descansa el sistema jurídico de un Estado, legitimando la actividad de los órganos estatales y dotándolos de competencia. ${ }^{63}$

En este sentido, el orden jurídico no es un sistema de normas de derecho situadas en un mismo plano, ordenadas equivalentemente, sino una construcción escalonada de diversos estratos de normas jurídicas. ${ }^{64}$

Según el principio de jerarquización normativa, en un sistema jurídico las normas superiores pueden determinar no sólo el órgano

${ }^{61}$ Ibídem, p. 54.

${ }^{62}$ Schmill Ordóñez, Ulises, El sistema de derecho y sus implicaciones, en Historia del Derecho, México, Instituto Mora, 1992, pp. 224 y 225.

${ }^{63}$ Huerta, Carla, Constitución, transición y ruptura, Transiciones y diseños institucionales, Op. Cit., p. 54.

${ }^{64}$ Kelsen, Hans, Teoría Pura del Derecho, trad. de Roberto J. Vernengo, UNAM- 
y el procedimiento según los cuales serán creadas las normas inferiores sino también el contenido de dichas normas. ${ }^{65}$

Si examinamos la validez de las normas, la dirección que sigue el proceso va de abajo hacia arriba, de tal manera que el fundamento de validez de una norma radica siempre en una norma superior que permite la creación de la norma inferior. ${ }^{66}$

El criterio de jerarquización permite, además, determinar la fuerza y eficacia de la norma. Todas las normas, independientemente de su posición y de la relación de supra o subordinación derivada de su jerarquía, se encuentran limitadas por el sistema jurídico. Es por ello que la validez de las normas del sistema depende de la Constitución; sin embargo, en el caso de la Constitución, a diferencia de las otras normas, la legitimidad será presupuesto de su validez, y su consecuencia será la eficacia, no lo que determine un órgano constituyente, ya que su origen puede ser pacífico o violento ${ }^{67}$

Ahora bien, en cuanto a la sustitución de un sistema jurídico por otro, "este se verifica cuando cambia la base, es decir, las normas primarias que reconocen los órganos primarios. Esto puede deberse a una decisión política de cambio o aun movimiento armado, como podría ser una revolución o un golpe de Estado, es decir, por actos de violencia que se traduzcan en el cambio de los órganos primarios". 68

IIJ, México, 1982, p. 232.

${ }^{65}$ Ost, Francois y Van de Kerchov, Michel, Elementos para una teoría crítica del derecho, Colombia, Universidad Nacional de Colombia, 2001, p. 117. Vid también, Kelsen, Hans, Teoría Pura del Derecho, Op. Cit., p. 201.

${ }^{66}$ Ibídem, Ost, Francois y Van de Kerchov, Michel, p. 118; Kelsen, Hans, p. 202.

${ }^{67}$ Cfr. Huerta, Carla, "Constitución, transición y ruptura", Transiciones y disenos institucionales, Op. Cit., p 59 y ss.

${ }^{68}$ Ibídem, p. 66. 
Por lo tanto, en el caso de nuevas disposiciones normativas contrarias a las anteriores, que establezcan nuevos órganos de gobierno, la validez del nuevo sistema depende más de su legitimidad y de su eficacia que de su procedimiento de creación. ${ }^{69}$

Ahora bien, "la idea de sistema jurídico se funda en una concepción lineal de tipo horizontal en la cual podemos ir hacia adelante y hacia atrás para la determinación de la norma aplicable al caso. El principio regulador es la dinámica; el sistema se crea y se recrea, modificándose de conformidad con los procedimientos que el mismo prevé". ${ }^{70}$

"Se puede decir que hay un cambio de sistema cuando hay una "ruptura", la cual se encuentra vinculada a la vigencia y eficacia de la norma fundamental; no así en el caso de una reforma, ya que ésta es propia de la dinámica del derecho." 71

Esto es la denominada "revolución jurídica"; desde el punto de vista de Zippelius. Es decir, la modificación extralegal de los principios fundamentales del orden existente. ${ }^{72}$

Por tanto, si el sistema se cambia extralegalmente, estaremos ante un fenómeno social (revolución), según lo refiere Zippelius, o una ruptura del sistema jurídico, según Carla Huerta, y en este caso, el nuevo sistema jurídico obtiene validez por el reconocimiento de sus disposiciones normativas y por el seguimieto que de ellas lleva a cabo el grupo de individuos al cual se dirigen; es decir, por la legitimidad y por la eficacia. Dejando de lado los mecanismos legales de creación de normas del antiguo sistema jurídico.

Si por el contrario, los cambios en el sistema se llevan a cabo de

69 Ídem.

${ }^{70}$ Ibídem, p. 63.

${ }^{71}$ Ibídem, p. 79.

72 Zippelius, Reinhold, Teoría del Estado. Ciencia de la Política, México, Porrúa, 2017 , p. 136. 
conformidad con la normatividad, entonces estaremos ante una reforma, mas no ante una revolución. Lo que significa que el sistema permanece válido.

XI. SISTEMA JURÍDICO Y DOGMÁTICA JURÍDICA

Este apartado es importante para distinguir el sistema jurídico normativo del sistema científico del derecho, y poder comprender, la relación de la cultura jurídica con ambos.

Rolando Tamayo señala que existen cuando menos, dos sistemas de significación jurídica: el sistema de las normas jurídicas que proporciona la significación jurídica prescriptiva y el sistema de los enunciados jurídicos que proporciona la significación jurídico-cognoscitiva. ${ }^{73}$

En ese orden de ideas, el primero en señalar la distinción entre norma y proposiciones normativas fue Bentham, quien distinguió el imperativo autoritativo de las formulaciones no autoritativas que se encuentran en los libros escritos por particulares, pero no por el legislador. ${ }^{74}$

En la obra de Kelsen aparece la distinción crucial entre norma jurídica y proposición jurídica. La norma jurídica es creada por la autoridad normativa; no es verdadera ni falsa, pero válida o inválida y también eficaz o ineficaz. La proposición jurídica es formulada por la ciencia del Derecho, es descriptiva, y por lo tanto, verdadera o falsa, pero no es válida ni inválida, ni tampoco puede ser obedecida o desobedecida. ${ }^{75}$

Alf Ross también hace la distinción señalando que las normas jurídicas son expresiones sin significado representativo pero son usadas

${ }^{73}$ Cfr. Tamayo y Salmorán, Rolando, Sobre el sistema jurídico y su creación... Op. Cit., p. 38.

${ }^{74}$ Alchourron Carlos y Bulygin, Eugenio Análisis lógico y Derecho, Op. Cit., p. 176.

${ }^{75}$ Cfr. Kelsen, Hans, Teoría Pura del Derecho, Op. Cit., p. 82 y ss. 
con el propósito de ejercer influencia, mientras que las proposiciones de la ciencia del Derecho son aserciones, esto es, expresiones con significado representativo. Hart, por su parte, habla de los enunciados internos (normas) y los externos (proposiciones normativas). ${ }^{76}$

No obstante lo anterior, existen autores como Giovani Tarello, para quien el derecho no debería entenderse sólo como el conjunto de enunciados normativos emanados del legislador, sino más bien el conjunto de las normas que de estos enunciados recaben los intérpretes. ${ }^{77}$

De igual forma, para Klaus Adomeit, la dogmática o ciencia del derecho también forma parte del sistema jurídico, ya que las proposiciones jurídicas deben estar basadas en el contenido de la norma, e incluso en algunos casos pueden llegar a ejercer influencia en la aplicación del derecho. ${ }^{78}$

En nuestra opinión, identificar al derecho, como sistema normativo, con la dogmática jurídica no es acertado; ya que si bien ambos son sistemas, uno de ellos es prescriptivo y el otro es descriptivo. Por tanto, la significación jurídica en cada caso es diferente. Las normas jurídicas obligan, prohíben o permiten determinadas conductas, que deben ser obedecidas independientemente de que el sujeto al que se dirigen lo quiera o no; las proposiciones o enunciados de la ciencia del Derecho no son obligatorias, de tal manera que, su contenido sólo constituye una referencia para los operadores del derecho.

En ese sentido, la distinción en el ámbito del derecho y el ámbito del conocimiento del derecho no es muy frecuente entre los juris-

76 Alchourron Carlos y Bulygin, Eugenio Análisis lógico y Derecho, Op. Cit., p. 178.

${ }^{77}$ Cfr. Tarello, Giovani, Cultura jurídica y política del derecho, trad. de Isidro Rosas Alvarado, FCE, México, 1995, p. 23.

${ }^{78}$ Cfr. Adomeit, Klaus, Introducción a la teoría del derecho, lógica normativa, teoría del método, politología jurídica, Editorial Civitas, España, 1984, p. 41 y ss. 
tas, pues por ejemplo, con el sintagma "derecho penal" los juristas pueden estar pensando tanto en el conjunto de normas o en un conjunto de proposiciones acerca de las normas. ${ }^{79}$

De lo anterior, y para efectos de nuestra investigación, podemos decir que un sistema jurídico es un conjunto de normas vinculadas entre sí, por una fuente común que permite que se constituya una unidad, así como la introducción de cambios en dicho sistema. ${ }^{80}$ Por su parte, la dogmática jurídica es una ciencia que tiene por objeto de estudio las normas que conforman el sistema jurídico.

Por tanto, los sistemas de significación jurídica que hemos analizado se refieren al sistema de normas de un Estado y el otro consistente en el estudio científico que se hace sobre las normas jurídicas. La confusión para los juristas y abogados radica en que ambos sistemas son denominados como Derecho; sin embargo la diferencia estriba en que uno es normatividad y el otro es ciencia.

Ahora bien, existe otro nivel vinculado con el derecho y la ciencia del derecho, llamado Filosofía del Derecho.

Para Tamayo y Salmorán, la Filosofía del Derecho tiene por objeto de estudio a la dogmática jurídica. En otros términos, el examen de los dogmas y presupuestos que subyacen detrás de los conceptos y métodos de la dogmática jurídica, así como de sus implicaciones. La Filosofía del Derecho deviene en una reflexión de segundo orden, constituyendo un análisis conceptual como epistemología crítica. $^{81}$

${ }^{79}$ Para un análisis sobre la dogmática jurídica y el derecho, Vid. Lariguet, Guillermo, Dogmática jurídica y aplicación de normas, México, Distribuciones Fontamara, 2007 , p. 40.

${ }^{80}$ Alchourrón, Carlos y Bulygin, Eugenio Análisis lógico y Derecho, Op. Cit., pp. 476 y 477.

81 Tamayo y Salmorán, Rolando, Elementos para una Teoría General del Derecho, Op. Cit., p. 294. 
En el siguiente apartado se presenta un esquema con los niveles de significación jurídica y su relación con la cultura jurídica.

XII. LA CULTURA JURÍdICA

En este apartado trataremos de explicar la relación que existe entre el sistema jurídico y la cultura, cuyo resultado, como veremos, es la propia cultura jurídica.

El adjetivo jurídico, sirve para señalar que algo se encuentra dentro del campo del derecho, pero además también en el ámbito de la ciencia y de la filosofía del derecho. De tal manera, que la cultura jurídica es esa parte de la cultura que se encuentra relacionada con el derecho.

Tal y como lo señala López Ayllón, ${ }^{82}$ es difícil hablar de "cultura jurídica”, ya que el concepto se aplica a una gran variedad de fenómenos; además, la cultura jurídica es sumamente difícil de investigar, ya que la información básica y los estudios existentes sobre ella no son homogéneos.

Para Nelken, el término cultura jurídica es extensamente utilizado por los académicos. Aunque esto sugiere la necesidad del término, los usos no necesariamente prueban su utilidad. En un principio, el término se utiliza indudablemente en una variedad de formas inconsistentes, y su popularidad puede demostrar más la falta de algo mejor, que algún mérito intrínseco. ${ }^{83}$

82 López Ayllón, Sergio, Las transformaciones del sistema jurídico y los significados sociales del derecho en México: la encrucijada entre tradición y modernidad, México, UNAMIIJ, 1997, p. 238.

${ }^{83}$ Nelken, David, Repensando el concepto de cultura jurídica, en Sociología del Derecho. Culturas y sistemas jurídicos comparados. Volumen II. Regulación, cultura jurídica, multiculturalismo jurídico y derechos humanos, Instituto de Investigaciones Jurídicas, UNAM, México, 2010. 
El mismo Friedman señala que los juicios sobre cultura jurídica descansan sobre evidencias poco convincentes. ${ }^{84}$ De acuerdo con este autor, la cultura jurídica consiste en las actitudes de la gente hacia el derecho y el sistema jurídico, sus creencias, valores, ideas y expectativas, es decir, es esa parte de la cultura general que concierne al sistema jurídico. En otras palabras, la cultura jurídica es el conjunto de pensamientos y fuerzas sociales que determinan cómo se usa, se evita o se abusa del derecho. ${ }^{85}$

Para Giovani Tarello la cultura jurídica es el conjunto de las técnicas expositivas y de las técnicas interpretativas de los que se ocupan del derecho, tanto prácticas como teóricas, y el conjunto de ideologías referentes a la función del derecho que tales técnicas sobreentienden. ${ }^{86}$

La cultura jurídica puede ser dividida en cultura jurídica "interna", y cultura jurídica "externa". La primera, es aquella que está constituida por el conjunto de valores, de principios, y de ideologías que se refieren al derecho, así como por el léxico propio de las profesión jurídica, es decir, de los operadores del derecho (aplicadores e intérpretes); la segunda, es aquella que consiste en las opiniones del público sobre el derecho, es la que se encuentra en las personas que no están vinculadas de manera directa con el sistema jurídico, es decir, son destinatarios del derecho. ${ }^{87}$

Esta misma división de la cultura la da Friedman, quien distingue también entre cultura jurídica interna y cultura jurídica externa. La primera la entiende como las creencias, opiniones y expectativas de aquellas personas que él considera operadores del sistema

${ }^{84}$ Friedman, Lawrence M., American Law, W.W. Norton and Company, United States of America, 1984, pp. 5-7.

${ }^{85}$ López Ayllón, Sergio, "Social and legal studies", Notes on mexican legal culture, International Journal, vol. 4, num. 4, diciembre de 1995, p. 477.

${ }^{86}$ Tarello, Giovani, Cultura jurídica y politica del derecho, Op. Cit., p. 24.

${ }^{87}$ Idem. 
jurídico, como son: abogados, jueces, magistrados y la cultura jurídica externa, que serían las creencias, expectativas y opiniones del común de las personas. ${ }^{88}$

Esta división permite hacer la separación entre la cultura de quienes se vinculan directamente con el sistema jurídico, es decir, los operadores del derecho (aplicadores, intérpretes y difusores); y quienes que no se encuentran vinculados directamente con el derecho, es decir la sociedad en general. Postura que hemos adoptado para el análisis de la cultura jurídica en México.

El derecho y la cultura se relacionan de múltiples formas, ${ }^{89}$ dando surgimiento a la cultura jurídica, como en el caso de los siguientes ejemplos: ${ }^{90}$

${ }^{88}$ Friedman, Lawrence M. "Legal Culture and Social Development", Law and Society, U.S.A. 1969, pp. 29-44.

${ }^{89}$ Esta relación entre Derecho y Cultura produce los siguientes conceptos: Cultura jurisdiccional. -En este caso, jurisdicción proviene del latín iuris dictio, que significa decir o declarar el derecho. De ahí que, la jurisdicción es la potestad derivada de la soberanía del Estado de aplicar el derecho. Por lo que es una facultad exclusiva de los Tribunales. En ese contexto, la cultura jurisdiccional se refiere a las formas de actuar de los órganos del Estado; en específico para ejercer la potestad de aplicar las normas generales al caso concreto por los Tribunales. Vid. Agüero Nazar, Alejandro, Las categorías básicas de la cultura jurisdiccional, en Cuadernos de Derecho Judicial, No. 6, 2006, pp. 19 a 58. Cultura judicial. -Es el conjunto de nociones, que arraigadas en una sociedad, reflejan el derecho de ésta. Esto es, son los modos de pensar, sentir y actuar de los operadores del derecho y de la sociedad en general en relación con el concepto de justicia. Cfr. Narváez, José Ramón, Cultura Furídica. Ideas e imágenes, México, Porrúa, 2010. p. 11. Cultura constitucional. -Constituye la suma de actitudes y de ideas, de expectativas subjetivas y de las correspondientes acciones objetivas tanto a nivel personal del ciudadano como al de sus asociaciones, al igual que al nivel de órganos estatales y al de cualquiera otro relacionado con la constitución. Es decir, la cultura constitucional son las formas de pensar, sentir y actuar tanto de los órganos del Estado como del ciudadano en relación con las disposiciones contenidas en la Constitución. Cfr. Häberle, Peter, Teoría de la constitución como ciencia de la cultura, España, Tecnos, 2000, p. 34.

90 Narváez, José Ramón, Cultura furídica. Ideas e Imágenes, México, Porrúa, 2010, pp. 4 a 6. 
- Como un bien jurídico.

- Como civilización.

- Como proceso de aculturación.

- Como parámetro axiológico del derecho.

- Como fuente del derecho.

- Como fenómeno cultural (tradición).

- Como ordenamiento constitucional.

- Como metodología aplicable a la ciencia jurídica.

- Como filosofía del lenguaje.

En ese orden de ideas, aunque la cultura jurídica es entendida de tantas formas distintas, Giorgio Rebuffa señala que podemos sintetizarla a las siguientes: conjunto de técnicas de exposición e interpretación utilizadas por los operadores el derecho; conjunto de ideologías que corresponden a las funciones del derecho; también es el conjunto de opiniones del público respecto del derecho positivo; conjunto de valores, principios y conocimientos de los profesionales del derecho y el conjunto de diferencias "nacionales" y locales en el pensamiento y la práctica jurídica. ${ }^{91}$

La diferencia que vamos a establecer con las definiciones anteriores radica en la posición de la cultura y del sistema jurídico, es decir, la cultura jurídica es un subsistema de la cultura en general, pero con relación al derecho, y que está constituida por el conjunto de maneras de pensar de sentir y de actuar de las personas que se relacionan de manera directa con el sistema jurídico (operadores del derecho); así como por las maneras de pensar, de sentir y de actuar de las personas que se relacionan indirectamente con el sistema jurídico (destinatarios del derecho).

Un concepto de cultura jurídica adecuado haría desechar reduccionismos muy comunes en visiones legalistas, que identifican cultu-

${ }^{91}$ Rebuffa, Giorgio, y Blankenburg, Erhard, "Culture Juridique", citados por López Ayllón, Las Transformaciones del sistema jurídico... Op. Cit., p. 238. 
ra jurídica con cultura de la legalidad, la cual supone la necesidad de infundir en todos los ciudadanos un temor reverencial hacia la ley, fruto de su conocimiento sistemático. A esta visión le falta la concepción antropológica que vincule el derecho a la sociedad. ${ }^{92}$

La cultura jurídica puede ser un concepto útil en la medida en que nos permita vincular el derecho a la sociedad. ${ }^{93}$ Permitiendo que lo jurídico se transforme para beneficio de las personas. Mejorando la imagen que del derecho pueda tener un conglomerado social.

Hablando de un concepto de cultura jurídica, tendríamos que decir que debe abarcar rasgos o características que no se alejen del mundo del derecho, ya que se corre el riesgo de hacer de la cultura jurídica algo no jurídico. Lo que significa que la cultura jurídica siempre deberá de enmarcarse dentro de la norma jurídica, la jurisprudencia, la costumbre, la dogmática jurídica, los principios del derecho, la historia del derecho, la sociología jurídica o la filosofía jurídica.

En nuestra opinión, el sistema jurídico es un reflejo de la cultura en general. Ambos (cultura y sistema jurídico) son creadores de la cultura jurídica. Pero la relación de la cultura no sólo es con la norma jurídica, sino también con la ciencia y la filosofía.

Para un mejor entendimiento de la cultura jurídica recurriremos al cuadro de los niveles del lenguaje de Rolando Tamayo. ${ }^{94}$ Así como al modelo de T.W. Moore, del edificio de varios niveles. ${ }^{95}$ De tal manera que, los sistemas de significación jurídica abarcan tres dimensiones:

92 Narváez, José Ramón, Cultura furídica. Ideas e Imágenes, Op. Cit., p. 8.

93 Ídem.

94 Tamayo y Salmorán, Rolando, Elementos para una Teoría General del Derecho, "Introducción al estudio de la Ciencia furídica", Themis, México, 1996, p. 295.

${ }^{95}$ Moore, T.W., Introducción a la teoría de la educación, España, Alianza Editorial, 1980, p. 19. 
1. La norma jurídica,

2. La ciencia jurídica, y

3. La filosofía jurídica.

\begin{tabular}{|l|l|l|}
\hline $\begin{array}{l}\text { Nivel 3 } \\
\text { Meta-meta-lenguaje }\end{array}$ & $\begin{array}{l}\text { Filosofía } \\
\text { jurídica. }\end{array}$ & $\begin{array}{l}\text { Análisis y comprobación de } \\
\text { los conceptos y métodos de la } \\
\text { ciencia jurídica. }\end{array}$ \\
\hline $\begin{array}{l}\text { Nivel 2 } \\
\text { Meta-lenguaje }\end{array}$ & $\begin{array}{l}\text { Dogmática } \\
\text { Jurídica. }\end{array}$ & $\begin{array}{l}\text { La descripción y explicación } \\
\text { del derecho positivo. }\end{array}$ \\
\hline $\begin{array}{l}\text { Nivel 1 } \\
\text { Lenguaje }\end{array}$ & $\begin{array}{l}\text { Norma } \\
\text { Jurídica. }\end{array}$ & $\begin{array}{l}\text { El derecho como un sistema } \\
\text { normativo. }\end{array}$ \\
\hline
\end{tabular}

La cultura jurídica es un conjunto de maneras de pensar, de sentir y de actuar de los operadores del nivel 1, 2 y 3 . Esto quiere decir, que la cultura jurídica abarca tanto a los operadores del derecho, es decir, abogados, jueces, fiscales, notarios, legisladores, etcétera; como a los académicos, en el nivel de ciencia del derecho, y en el de la filosofía jurídica.

Por supuesto que la cultura jurídica también incluye las formas de pensar, sentir y actuar de la sociedad en general respecto del mundo del derecho.

En ese sentido, la cultura jurídica está constituida por las formas de pensar, sentir y actuar de los operadores del derecho, de los científicos del derecho y de los filósofos del derecho, así como de la sociedad que se encuentra vinculada a un sistema normativo determinado.

En tanto que el sistema jurídico es un conjunto organizado de disposiciones normativas que sólo hace referencia al nivel de operatividad. Esto es, al nivel 1 de nuestro cuadro.

Para mayor claridad, el derecho es un sistema normativo. Esas normas jurídicas son creadas por los órganos del Estado en sus tres funciones: Legislativa, Judicial y Ejecutiva. Llámese ley, código, reglamento, circular, decreto, jurisprudencia o sentencia. Sin embargo, el derecho también es un sistema científico, que contiene 
la sistematización de conocimientos acerca del objeto de estudio llamado normas jurídicas. Por tanto, el derecho tiene una doble significación como norma jurídica y como ciencia. El primero es el sistema normativo, y el segundo, el sistema científico, también llamado dogmática jurídica.

Además existe otra significación jurídica, que no es ni la norma, ni la ciencia, sino la filosofía jurídica; cuyo objetivo es estudiar los postulados de la dogmática jurídica. En este caso, es importante aclarar que estamos ante un sistema filosófico, no dogmático jurídico, ni normativo.

Esto se puede esquematizar de la siguiente forma:

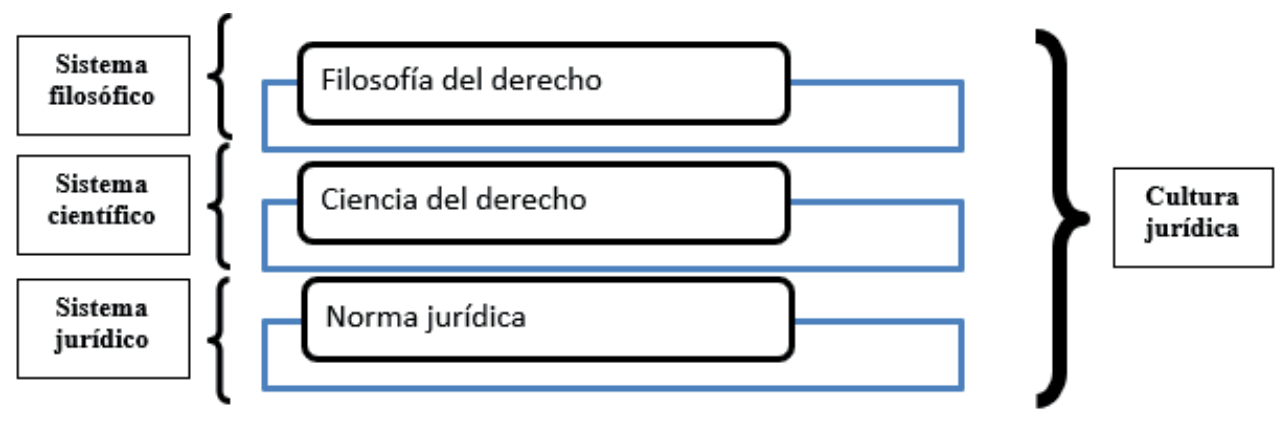

En todo este contexto, la cultura jurídica está conformada por los pensamientos, sentimientos y actitudes sobre los tres sistemas de significación jurídica: normativo, dogmático y filosófico; es decir, constituye una visión integral y sistémica del derecho.

Xill. Conclusiones

Primera. En el lenguaje ordinario, la cultura es entendida como el resultado o efecto de cultivar los conocimientos humanos y de afinar o desarrollar por medio del ejercicio las facultades intelectuales del hombre. En el lenguaje científico de la sociología, antropología y etnología, el vocablo cultura adquiere un significado más amplio; constituye un sistema de pensamientos, sentimientos, actitudes y ac- 
ciones, que posee o lleva a cabo una sociedad, que la hace poseer características peculiares y distintas, que la convierten en única.

Segunda. El vocablo "cultura", de uso tan generalizado en la actualidad, ha sufrido cambios en su significado según la época y el país. En Italia, en el siglo XV la palabra cultura se emplea como parte de cultivo; en Francia, en la edad media, el término culture significaba el culto religioso y en el siglo XVII, indicaba el trabajo de la tierra. Fue hasta el siglo XVIII, cuando los escritores franceses comenzaron a utilizar el término para designar la formación del espíritu. En Alemania, el término Kultur designaba además del progreso intelectual del hombre, su evolución en lo social. En el siglo XIX y XX, en Inglaterra y Estados Unidos, se asoció al término civilización.

Tercera. La noción de cultura se refiere a una sociedad dada e identificable que aglutina las creencias, instituciones, técnicas, ciencia, derecho, economía, política, etcétera; mientras que el término civilización sirve para designar un conjunto de sociedades o culturas; un tipo de sociedad cuya característica principal es su complejidad social manifestada en lo urbano, y la asociación con las formas de pensar, sentir o actuar de Occidente.

Cuarta. Todos los sistemas tienen en común el hecho de que sus elementos constituyentes son compatibles y de que todos los elementos están determinados entre sí. Lo anterior significa que, cuando varios elementos tienen un origen común, así como una conexión entre sí se puede determinar un sistema.

Quinta. Un sistema jurídico es un conjunto de normas que se encuentran relacionadas por una fuente común, que es la que proporciona la unidad y fundamento al propio sistema. Por ejemplo, ese fundamento puede ser una Constitución (Kelsen), un legislador Soberano (Austín), una Regla de Reconocimiento (Hart), los Órganos Primarios (Raz), o un Acto-Condición (Tamayo). 
Sexta. Una norma eficaz no convierte en eficaz al sistema jurídico; sin embargo, una gran cantidad o la mayoría de normas eficaces, sí lo hace válido. Por otro lado, una norma aislada puede ser válida aunque no sea eficaz. Un sistema jurídico adquiere validez necesariamente a través de la eficacia generalizada. La norma jurídica aislada puede ser válida de dos formas: que el sistema formalmente la declare válida o que sea eficaz junto con la mayoría de las normas del sistema; en este caso, el sistema se volverá válido y todas sus normas también.

Séptima. El sistema jurídico es el continente de todas las normas de un país tanto vigentes como no vigentes y el orden jurídico representa los cortes transversales que generan un nuevo contexto normativo. Un sistema está conformado por varios órdenes jurídicos; generalmente iniciados a partir de la misma base normativa.

Octava. Si el sistema jurídico se modifica extralegalmente, estaremos ante una revolución o una ruptura; en este caso, el sistema jurídico obtiene validez por el reconocimiento de sus disposiciones normativas y por el seguimiento que de ellas lleva a cabo el grupo de individuos al cual se dirigen; es decir, por la legitimidad y por la eficacia; dejando de lado los mecanismos legales de creación de normas del antiguo sistema jurídico.

Novena. Existen dos sistemas de significación jurídica que suelen confundirse, uno es el sistema de normas de un Estado y el otro consistente en el estudio científico que se hace sobre las normas jurídicas. Ambos son identificados con el vocablo "Derecho", sin embargo, uno es propiamente un sistema jurídico normativo, y el otro, la dogmática jurídica o ciencia del Derecho.

Décima. La cultura jurídica está constituida por las formas de pensar, sentir y actuar de los operadores del derecho, de los científicos del derecho y de los filósofos del derecho, así como de la sociedad que se encuentra vinculada a un sistema normativo determina- 
do. El sistema jurídico está conformado por las normas jurídicas de un Estado, sin incluir las proposiciones de la Dogmática Jurídica. No obstante, la cultura jurídica constituye una visión integral que abarca tanto al sistema normativo, como al sistema científico y filosófico del derecho.

Xiv. Fuentes

1. Bibliografía

Acero, Juan José, "Introducción: concepciones del lenguaje”, Filosofía del lenguaje I. Semántica, Editorial Trota, España, 1998.

Adomeit, Klaus, Introducción a la teoría del derecho, lógica normativa, teoría del método, politología jurídica, Editorial Civitas, España, 1984.

Alchourron, Carlos y Bulygin, Eugenio, Análisis lógico y Derecho, España, Centro de Estudios Constitucionales, 1991.

Alexi, Robert, El concepto y la validez del derecho, España, Editorial Gedisa, 1997.

Braudel, Fernand, Las civilizaciones actuales. Estudio de la historia económica y social, España, Tecnos, 1999.

Austin, John, Sobre la utilidad del estudio de la jurisprudencia, México, Supremo Tribunal de Justicia del Estado de Sinaloa, 1998.

Diccionario de Sociología, primera edición, cuarta reimpresión, T. II, trad. T. Muñoz et al, FCE, México, 1971.

Diccionario Medieval Español, Traducción: Mujeres Ilustres. España, Bocaccio, 1994.

Duverger, Maurice, Sociología política, España, Editorial Ariel. $3^{\text {ra }}$ edición, 1980. 
Elías, Norbert, El proceso de la civilización. Investigaciones sociogenéticas y psicogenéticas. México, Fondo de Cultura Económica, 2012. , Sociología fundamental, Gedisa Editorial, México, 2011.

Fabvre, Lucien, et al, Civilisation: le mot et l'idée, France, Centre Internacional de Synthé, 1930.

Ferrater Mora, José, Diccionario de Filosofia, España, Editorial Ariel, 2004.

Friedman, Lawrence M., American Law, W.W. Norton and Company, United States of America, 1984.

García Rivas, Heriberto, Historia de la Cultura en México, Textos Universitarios México, 1990.

HäBerle, Peter, Teoría de la constitución como ciencia de la cultura, España, Tecnos, 2000.

Hierro, Liborio, La eficacia de las normas jurídicas, México, Distribuciones Fontamara, 2010.

Huerta, Carla, "Constitución, transición y ruptura", Transiciones y diseños institucionales, María del Refugio González y Sergio López Ayllón compiladores, UNAM-IIJ, México, 1999.

Huntington, Samuel, El Choque de Civilizaciones y la Reconfiguración del Orden Mundial, España, Paidós, 1997.

Kelsen, Hans, Teoría General de las Normas, México, México, Trillas, 1994. , Teoría General del Derecho y del Estado, Trad. de Eduardo García Máynez, UNAM, México, 1998.

, Teoría Pura del Derecho, trad. de Roberto J. Vernengo, UNAMIIJ, México. 1999.

Lariguet, Guillermo, Dogmática jurídica y aplicación de normas, México, Distribuciones Fontamara, 2007. 
López Ayllón, Sergio, Las transformaciones del sistema jurídico y los significados sociales del derecho en México: la encrucijada entre tradición y modernidad, México, UNAM-IIJ, 1997.

Lugan, Jean Claude, La systémique sociale, France, Presses Universitaries de France, 2009.

Luhmann, Niklas, Introducción a la teoría de sistemas, Universidad Iberoamericana, México, 2009.

, Sistemas Sociales. Lineamientos para una teoría general, México, Universidad Iberoamericana-Alianza Editorial, 1991.

Moliner, María, Diccionario del uso del español, España, Editorial Gredos, España, 2013.

NArváez, José Ramón, Cultura furídica. Ideas e Imágenes, México, Porrúa, 2010.

Nelken, David, "Repensando el concepto de cultura jurídica, en Sociología del Derecho. Culturas y sistemas jurídicos comparados". Regulación, cultura jurídica, multiculturalismo jurídico y derechos humanos, Volumen II. México, UNAM, Instituto de Investigaciones Jurídicas, 2010 .

Odum, Howard W., Understanding society; the principles of dynamic sociology. England, Macmillan, 1947.

Ost, Francois y Van de Kerchov, Michel, Elementos para una teoría crítica del derecho, Colombia, Universidad Nacional de Colombia, 2001.

RAz, Joseph, El concepto de sistema jurídico, México, UNAM-IIJ, 1986. , La autoridad del derecho. Ensayos sobre derecho y moral, México, UNAM-IIJ, 1982. 
Real Academia Española, Diccionario de la lengua española, España, 2012.

Rocher, Guy, Introducción a la sociología general, $11^{\text {va }}$ edición, Editorial Herder, Barcelona España, 1990.

Ross, Alf, El concepto de validez y otros ensayos, México, Distribuciones Fontamara, 1991.

Schmill Ordóñez, Ulises, El sistema de derecho y sus implicaciones, en Historia del Derecho, México, Instituto José María Luis Mora, 1992.

Stebbing, Susan, Introducción moderna a la lógica, Centro de Estudios Filosóficos-UNAM, México, 1985.

TAMAyo y SAlmorán, Rolando, Sobre el sistema jurídico y su creación, UNAMIIJ, México, 1976.

, Elementos para una Teoría General del Derecho, "Introducción al estudio de la Ciencia Jurídica”, Themis, México, 1996.

Tarello, Giovani, Cultura jurídica y política del derecho, trad. de Isidro Rosas Alvarado, FGE, México, 1995.

TyLor, Edward Burnett, Primitive culture, USA, Dover publications, 2016.

Zippelius, Reinhold, Teoría del Estado. Ciencia de la Política, México, Porrúa, 2011.

2. Hemerografía

Friedman, Lawrence M., "Legal Culture and Social Development", Law and Society, U.S.A. 1969.

Larroyo, Francisco, "En memoria de Francisco Romero", Dianoia. Anuario de Filosofía, UNAM-FGE, Año IX, Núm. 9, México, 1993. 
López Ayllón, Sergio, "Social and legal studies", Notes on mexican legal culture, International Journal, vol. 4, num. 4, diciembre de 1995. 

Entrevistas 
